\title{
Effect of body build on weight-training-induced adaptations in body composition and muscular strength
}

Citation for published version (APA):

van Etten, L. M. L. A., Callens, S., \& Westerterp, K. R. (1994). Effect of body build on weight-traininginduced adaptations in body composition and muscular strength. Medicine and Science in Sports and Exercise, 26(4), 515-521. https://doi.org/10.1249/00005768-199404000-00018

Document status and date:

Published: 01/01/1994

DOI:

10.1249/00005768-199404000-00018

Document Version:

Publisher's PDF, also known as Version of record

\section{Document license:}

Taverne

\section{Please check the document version of this publication:}

- A submitted manuscript is the version of the article upon submission and before peer-review. There can be important differences between the submitted version and the official published version of record.

People interested in the research are advised to contact the author for the final version of the publication, or visit the DOI to the publisher's website.

- The final author version and the galley proof are versions of the publication after peer review.

- The final published version features the final layout of the paper including the volume, issue and page numbers.

Link to publication

\footnotetext{
General rights rights.

- You may freely distribute the URL identifying the publication in the public portal. please follow below link for the End User Agreement:

www.umlib.nl/taverne-license

Take down policy

If you believe that this document breaches copyright please contact us at:

repository@maastrichtuniversity.nl

providing details and we will investigate your claim.
}

Copyright and moral rights for the publications made accessible in the public portal are retained by the authors and/or other copyright owners and it is a condition of accessing publications that users recognise and abide by the legal requirements associated with these

- Users may download and print one copy of any publication from the public portal for the purpose of private study or research.

- You may not further distribute the material or use it for any profit-making activity or commercial gain

If the publication is distributed under the terms of Article 25fa of the Dutch Copyright Act, indicated by the "Taverne" license above, 


\title{
Effect of body build on weight-training- induced adaptations in body composition and muscular strength
}

\author{
LUDO M. L. A. VAN ETTEN, FRANS T. J. VERSTAPPEN, and \\ KLAAS R. WESTERTERP \\ Institute of Movement Sciences and \\ Department of Human Biology, \\ University of Limburg, \\ 6200 MD Maastricht, THE NETHERLANDS
}

\begin{abstract}
VAN ETTEN, L. M. L. A., F. T. J. VERSTAPPEN, and K. R. WESTERTERP. Effect of body build on weight-training-induced adaplittions in body composition and muscular strength. Med. Sci. Sports Exerc. Vol. 26, No. 4, pp. 515-521, 1994. The aim of the present study wals to investigate whether weight-training-induced adaptations in body composition and isokinetic strength differ as a function of body build. Body build of a subject was characterized as the extent to which a person's fat-free mass index (FFMI $=$ lat-free mass $\cdot h \mathrm{hight}^{-2} ; \mathrm{kg} \cdot \mathrm{m}^{-2}$ ) differs from the regression of FFMI over fat mass index (FMI $=$ fat mass height $\left.^{-2} ; \mathrm{kg} \cdot \mathrm{m}^{-2}\right)$ as derived from a sedentary male population $(N$ $=77)$. From this population two groups with either a slender $(N=10)$ or a solid $(N=11)$ body build were selected. For 12 wh the subjects performed a weight-training program twice a week. Training induced a significant $(P<0.05)$ increase in fat-frec mass (FFM) in the solid group $(1.6 \mathrm{~kg}, 2.3 \%)$ in contrast with the slender group, which showed no significant change in FFM. Both groups showed comparable decreases in fat mass (FM; slender: $-1.7 \mathrm{~kg},-10.8 \%$ versus solid: -2.4 $\mathrm{kg},-11.3 \%$ ) and increases in strength (on average $13.8 \%$ ). In conclusion, the increase in FFM due to a weight-training program is modified by body build. This modification, however, is restricted to a larger increase in the solidly built group.
\end{abstract}

BODY COMPOSITION, FAT-FREE MASS INDEX, FAT MASS INDEX, ISOKINETIC STRENGTH

$\mathrm{M}$ uscle, fat, and bone are the three major structural components that model the human body build. Visual differences in body dimensions among individuals are readily apparent, including differences in height, weight, and regional fat distribution (c.g., waist/hip ratio). Body composition differences, namely differences in fat-free mass (FFM) and fat mass (FM), may be less apparent. The actual body build of a subject is determined, in part, by genotype and physical activity. Leading a more active lifestyle, including both occupational and leisure time activities, positively in-

$0195-9131 / 94 / 26044-01515 \$ 3 .(601 / 0)$

MEDICINE AND SCIENCE IN SPORTS ANI) IEXERCISE

Copyright of 1094 by the Americin College of Sparts Medicine

Submitted for publicition November 1992.

Accepted for publication October (D)?. creases the FFM/FM ratio $(22,23,26)$. Furthermore, specific types of physical training lead to specific changes in body composition. Weight training mainly increases FFM whereas endurance-type activities mainly decrease FM (11). The relative contribution of genetics and the environment to body build are not well studied or quantified. In healthy individuals, the size of the skeleton and therefore height, can presumed to be mainly genetically determined.

Like body build, the ability to achieve a high level of sports performances is determined, in part, by genetic factors and physical training. Despite quality training, wide variability still exists in physical performance among elite athletes. Thus, coaches and sports medicine scientists are interested in the connection between body build and physical performance. Previous research (10) has reported the biometrical benefits of height, muscle mass (absolute quantity), and proportional body dimensions for a variety of sports. The benefit of using proportional dimensions is the possibility to compare individuals or groups irrespective of differences in height. Proportional dimensions mostly express the size of body parts relative to other bodily dimensions within a person, e.g., body mass index (BMI), which expresses weight relative to height $\left(\mathrm{kg} \cdot \mathrm{m}^{-2}\right)$. Sometimes bodily dimensions are also compared with reference values based on a large number of subjects. The somatogram introduced by Behnke and Wilmore (1) and the somatotype originated by Sheldon and modified by Heath and Carter (8) are examples of methods to describe body build by using proportional bodily dimensions relative to other dimensions as well as reference values.

The influence of body build is relevant to consider when the effect of different training programs, training methods, or equipment are compared. The response to the intervention may be biased by differences in initial body build of the experimental population. This can lead 
TABLE 1. Initial anthropometric characteristics of the different subject categories (recruited population, slender-group, solid-group) and the absolute differences between the slender- and solid-group ( $\mid$ dif $S \mid-$ Sol)

\begin{tabular}{|c|c|c|c|c|}
\hline Variables & $\begin{array}{l}\text { Recruiled } \\
(N=77)\end{array}$ & $\begin{array}{c}\text { Slender } \\
(N=10)\end{array}$ & $\begin{array}{c}\text { Solid } \\
(N=11)\end{array}$ & | dif SI - So \\
\hline Age (yr) & $34 \pm 4.8$ & $38 \pm 3.4$ & $34 \pm 4.7$ & $4.0^{\star}$ \\
\hline Weight (kg) & $83.9 \pm 11.5$ & $74.1 \pm 7.9$ & $90.2 \pm 9.7$ & $16.1^{* \star}$ \\
\hline Height (m) & $1.79 \pm 0.07$ & $1.80 \pm 0.04$ & $1.77 \pm 0.06$ & 0.03 \\
\hline $\mathrm{BMI}\left(\mathrm{kg} \cdot \mathrm{m}^{-2}\right)$ & $26.1 \pm 3.2$ & $22.6 \pm 3.7$ & $28.8 \pm 2.1$ & $6.2^{* *}$ \\
\hline Fat $(\%)$ & $24.0 \pm 5.6^{a, b}$ & $24.2 \pm 4.8^{b}$ & $23.0 \pm 4.2^{0}$ & 1.2 \\
\hline FFM $(\mathrm{kg})$ & $63.4 \pm 7.0$ & $55.9 \pm 4.1$ & $69.2 \pm 5.7$ & $13.3^{* *}$ \\
\hline$F M(\mathrm{~kg})$ & $20.5 \pm 6.5$ & $18.2 \pm 5.1$ & $21.0 \pm 5.5$ & 2.8 \\
\hline $\mathrm{FFMI}\left(\mathrm{kg} \mathrm{FFM} \cdot \mathrm{m}^{-2}\right)$ & $19.7 \pm 1.7$ & $17.1 \pm 1.2$ & $22.1 \pm 1.0$ & $5.0^{\star \star}$ \\
\hline $\mathrm{FMl}\left(\mathrm{kg} \mathrm{FM} \cdot \mathrm{m}^{-2}\right)$ & $6.4 \pm 2.1$ & $5.5 \pm 1.4$ & $6.7 \pm 1.6$ & 1.2 \\
\hline FFMI-FFMI ${ }_{\text {predicted }}\left(\mathrm{kg} \mathrm{FFM} \cdot \mathrm{m}^{-2}\right)$ & $0 \pm 1.5$ & $-2.3 \pm 1.2$ & $2.3 \pm 1.0$ & $4.6^{\star \star}$ \\
\hline
\end{tabular}

Values are means $\pm S D$ (level of significance: $* P<0.05,{ }^{*} P<0.01$ ).

Body composition was measured using skinfold thickness $\left({ }^{a}\right)$ or hydrostatic weighing $\left({ }^{(}\right)$.

to an over- or underestimation of the studied independent variables and thus to faise conclusions.

The aim of the present study was to investigate whether weight-training-induced changes in body composition and strength are a function of initial body build. Additionally, attention is paid to a possible relation between changes in bodily dimensions and physical performance. For this study two groups of healthy untrained sedentary males were selected with a contrasting body build described as the height-normalized quantity of FFM corrected for FM. Subsequently subjects trained two times a week for $12 \mathrm{wk}$. The response was measured by comparing body composition and strength before and after the intervention.

\section{METHODS}

Subjects. Subjects were healthy clerks recruited from various offices. The recruitment criteria were male sex, age between 25 and $45 \mathrm{yr}$, a sedentary lifestyle and not participating in a regular training program for at least $2 \mathrm{yr}$ prior to the study. Seventy-seven subjects met these criteria and gave their written informed consent. Body composition, FFM and FM, were calculated from skinfold thickness (3) and body mass (Table 1). From this recruited group two experimental groups (slender and solid group) were selected with contrasting body build.

Body build. The description of body build was based on a two-compartment model of body composition in which body weight is divided into FFM and FM. The active component FFM was used to describe body build. To allow comparisons between individuals, FFM was corrected for height and FM. FFM and FM relative to height were in analogy with the body mass index (BMI) expressed as fat-free mass index (FFMI $=$ FFM $\cdot$ height ${ }^{-2}$; $\mathrm{kg} \mathrm{FFM} \cdot \mathrm{m}^{-2}$ ) and fat mass index $\left(\mathrm{FMI}=\mathrm{FM} \cdot\right.$ height $^{-2}$; $\left.\mathrm{kg} \mathrm{FM} \cdot \mathrm{m}^{-2}\right)(24,26)$. In addition, BMI is equal to the sum of FFMI and FMI. To quantify the relationship between FFMI and FMI (6), FFMI was plotted as a function of FMI (Fig. 1). The regression equation expresses the quantitative relationship between FFMI and FMI $\left(\right.$ FFMI $_{\text {predicted }}=17.566+0.335(\mathrm{FMI}) ; \mathrm{r}=0.409 ; P<$
0.001 ). Individual body build was characterized on an interval scale by subtracting FFMI ${ }_{\text {predicted }}$ from the actual FFMI. The $60 \%$ prediction interval of FFMI given FMI (Fig. 1) was used to ensure a clear contrast in body build. After verifying body composition with the hydrostatic weighing technique, subjects beyond this prediction interval were assigned to either the slender group $(N=10$; actual FFMI < FFMI $\left.I_{\text {predicted }}\right)$ or solid group $(N=11$; actual FFMI $>$ FFMI $\left._{\text {predicted }}\right)$. Three subjects were excluded because of a FMI not within two standard deviations of the mean. For interpretation of the applied concept, examples of body build are given in Figure 2.

Body composition. After the selection procedure all measurements concerning body composition were taken the morning after a controlled overnight stay at the laboratory where the subjects abstained from eating and drinking for $14 \mathrm{~h}$.

Body mass was measured after emptying the bladder to an accuracy of $\pm 5 \mathrm{~g}$ on an electronic scale (Mettler, E1200). Body density was measured using the hydrostatic weighing technique with simultaneous measure-

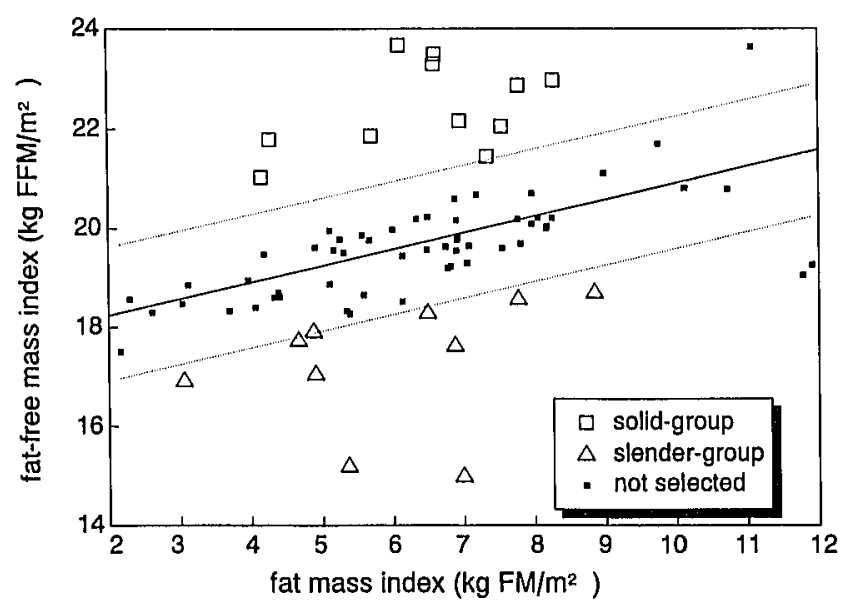

Figure 1-Fat-free mass index plotted as a function of fat mass index of the recruited population $\left(N=77\right.$ FFMI $_{\text {predicted }}=17.566+0.335$ * FMI; $r=0.409 ; P<0.001)$. The dotted lines are the borderlines of the $60 \%$ prediction interval of FFMI given FMI. Subjects beyond this interval were assigned to either the slender group $(N=10)$ or solid group $(N=11)$. 


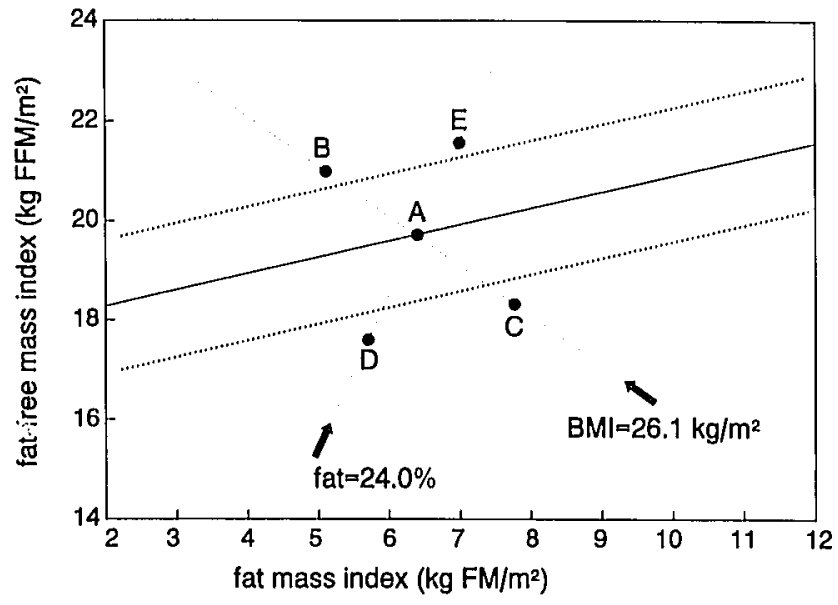

\begin{tabular}{crrr} 
Subject & Weight & Height (BMI) & \%Fat \\
\hline A & 83.8 & $1.793(26.1)$ & 24.0 \\
B & 83.8 & $1.793(26.1)$ & 19.5 \\
C & 83.8 & $1.793(26.1)$ & 29.8 \\
D & 74.9 & $1.793(23.3)$ & 24.0 \\
E & 91.6 & $1.793(28.5)$ & 24.0 \\
D & 83.8 & $1.896(23.3)$ & 24.0 \\
E & 83.8 & $1.714(28.5)$ & 24.0 \\
\hline
\end{tabular}

Figure 2-The effect of changes in weight, height, or \% fat on the body build of subject $A$ representing the mean anthropometric characteristics of the recruited group. Changes are printed in italics.

ment of residual lung volume with the helium dilution technique (Volugraph 200, Mijnhardt). Water density was corrected for temperature. Percent fat was calculated from body density assuming a FFM and FM density of 1.097 and $0.901 \mathrm{~kg} \cdot \mathrm{l}^{-1}$, respectively. This resulted in the following equation for percentage of fat:

$$
\operatorname{FAT}(\%)=\left(\frac{504.28}{\text { body density }}-459.69\right) \text {. }
$$

Muscular strength. Muscular strength in the upper thigh and shoulder/arm was measured using an isokinetic dynamometer (Cybex II) at several angular velocities: knee flexion and extension at 1.047, 3.142, and 4.189 $\mathrm{rad} \cdot \mathrm{s}^{-1}\left(60,180\right.$, and $240^{\circ} \cdot \mathrm{s}^{-1}$, respectively); shoulder/ arm during a bench press movement at 1.047 and 2.094 $\mathrm{rad} \cdot \mathrm{s}^{-1}\left(60\right.$ and $120^{\circ} \cdot \mathrm{s}^{-1}$, respectively). Subjects performed one set of five repetitions at each velocity from which the peak torque was noted as parameter for maximal strength.

Training program. The subjects trained independently, twice a week, on nonconsecutive days for $12 \mathrm{wk}$, using an individually prescribed training program based on the subject's weight and baseline performance at the respective exercises. The program consisted of $10 \mathrm{~min}$ warming up (cycling), 14 strength exercises using free weights and machine gym equipment (Table 2) and $5 \mathrm{~min}$ of cooling down (cycling) completed with stretching exercises. In weeks 2 and 3 the initial single set of 15 repetitions (reps) per exercise was doubled and tripled, respectively, without changing the training weight. Throughout weeks 4,5 , and 6 , training weight was adjusted as strength levels increased provided that the subjects were able to perform three sets of 15 reps. Thus, during the first $6 \mathrm{wk}$ the nature of the training program changed from familiarizing and skill development to more serious resistance training. From week 7 the design of the training program was furthermore adjusted for seven exercises (marked with a diamond ( ) in Table 2 ). The one repetition maximum (IRM) of the exercise was measured to adjust the training weights to $65-70 \%$ of 1RM (14). The number of repetitions per set was changed from 15 to 10 repetitions in the first two sets and an all-out effort in the third set (18). This all out effort was used as criterion to further adjustment of the training weight: less than seven reps the training weight was lowered and more than 13 reps the training weight was increased with one unit of weight $(2.5,5$ or $10 \mathrm{~kg}$, depending on the apparatus and muscle group used). In case of the unmarked exercises (Table 2), the adjustment procedure of the first $6 \mathrm{wk}$ was continued. The training program was regularly supervised by a fitness instructor to guide and encourage the subjects and to control the use of correct techniques. Maximal aerobic power was meas-

TABLE 2. Training protocol from weeks 1-12. Subjects trained independently, two times a week on nonconsecutive days

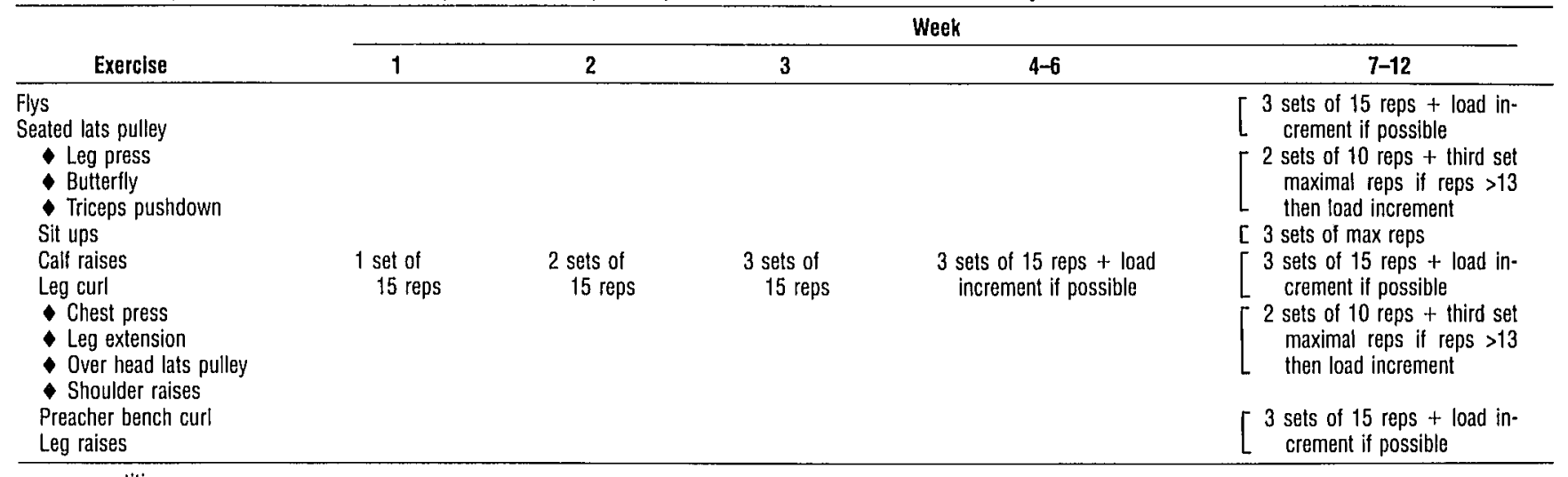

reps $=$ repetitions. 
ured before and after the training period with a progressive cycling test to consider the specificity of the training.

Statistical analysis. Unpaired and paired $t$-tests were used to analyze the differences between the groups and changes within a group, respectively. When comparing more than two population means, analysis of variance and the Student-Neuman-Keuls post-hoc test was used. A probability value of $P<0.05$ was considered significant.

\section{RESULTS}

In Table 3 the mean changes $(\Delta)$ on body composition are presented for: all subjects $(N=21)$, the slender group (Sl; $N=10$ ), the solid group (So; $N=11$ ), and the absolute differences between the slender and solid group (dif $|\mathrm{Sl}-\mathrm{So}|$ ). Changes (\%) relative to initial values are also presented because of initial differences in body composition and physical performance between the groups.

The entire group showed a significant change in body weight $(-1.1 \pm 2.1 \mathrm{~kg},-1.3 \pm 2.5 \%)$, FFM $(0.9 \pm 1.3$ $\mathrm{kg}, 1.5 \pm 2.0 \%)$ and $\mathrm{FM}(-2.1 \pm 1.7 \mathrm{~kg},-10.9 \pm 8.4 \%)$. An additional way to compare the changes in body composition is a comparison of the changes in body build. This method combines changes in FMI and FFMI and hence changes in FM and FFM since height remains the same. The entire group became a more solid body build after 12 wk of weight training. Regarding the subgroups, most of the within group changes were also significant except the changes in weight within the solid group and the changes in FFM within the slender group. Comparing the size of the changes between both subgroups, there is a significantly larger increase in FFM for the solid group $(1.6 \pm 1.4 \mathrm{~kg}$ vs $0.3 \pm 0.9 \mathrm{~kg}$ and $2.3 \pm 2.0 \%$ vs $0.5 \pm$ $1.7 \% ; P<0.05)$. The solid group also showed a significantly larger change in body build $\left(0.75 \pm 0.45 \mathrm{~kg} \cdot \mathrm{m}^{-2}\right.$ vs $0.26 \pm 0.30 \mathrm{~kg} \cdot \mathrm{m}^{-2} ; P<0.05$ ).

Before the training period, strength (maximal torque) differed significantly between the groups (Fig. 3), whereas strength relative to FFM ( $\left.\mathrm{Nm} \cdot \mathrm{kg}^{-1} \mathrm{FFM}\right)$ was similar at all movements tested. Strength, absolute as well as relative to FFM, significantly increased in both subgroups at all angular velocities and movements tested (Fig. 3). No significant difference in $\Delta$ strength between both subgroups has been found. The relative (\%) increase in strength in the knee extensor is significantly lower
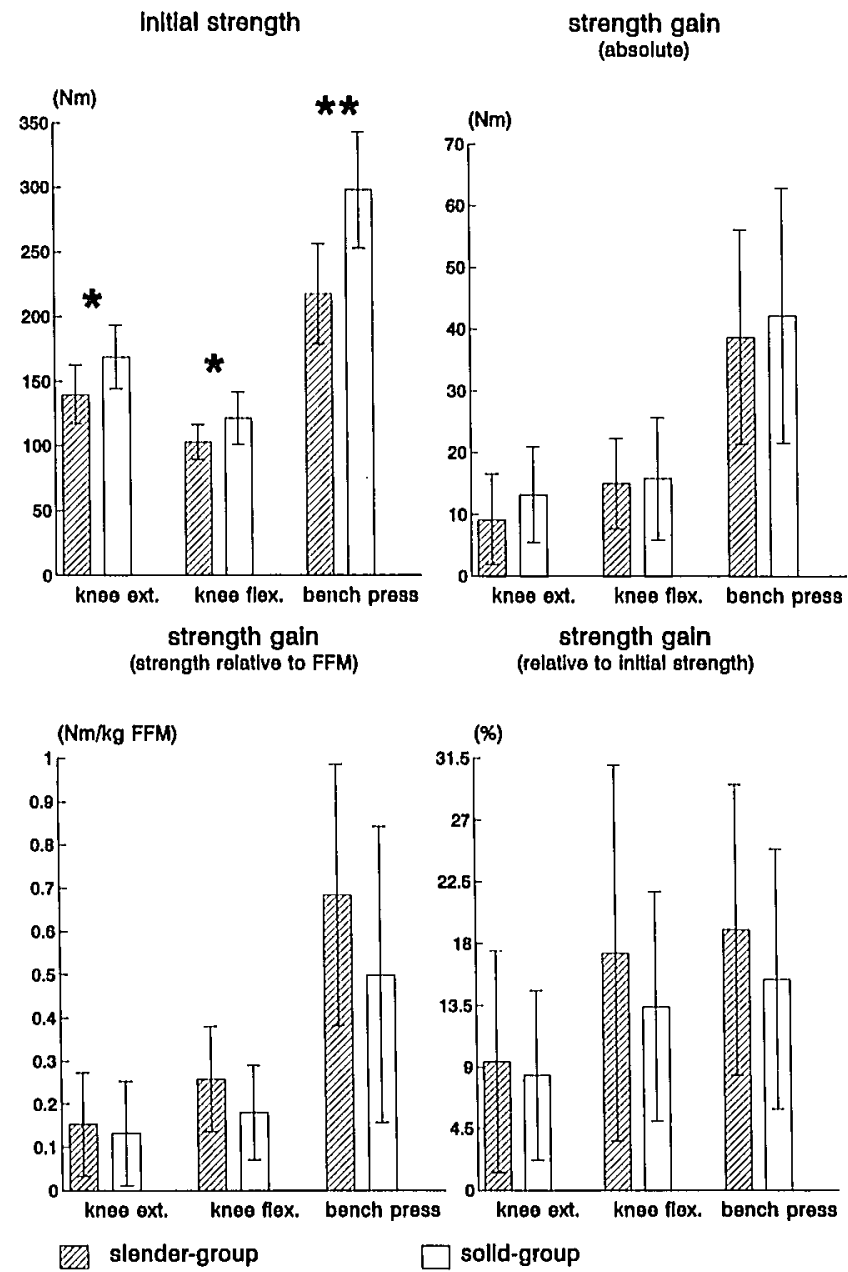

Figure 3-Initial data and changes (mean \pm SD) in strength at the three movements tested. The initial data differed between both group (*P $P<0.05$, ** $P<0.01)$. Strength was significantly increased $(P<0.001)$ in both subgroups but did not significantly differ between the slender and solid group. The knee extensor muscles showed a smaller strength gain than the knee flexor and arm/shoulder muscles $(P<0.01)$.

than the increase in the knee flexor and shoulder/arm muscles $(8.8 \pm 7.0 \%$ vs $15.3 \pm 11.2 \%$ and $17.1 \pm 9.9 \%)$. There was no significant correlation between initial strength and absolute $\Delta$ strength. Despite a highly significant correlation between initial FFM and the parameters of strength $(r=0.73,0.59$, and 0.85 for knee extension, knee flexion and shoulder/arm muscles, respectively: $P<$

TABLE 3. Changes in weight, fat-free mass (FFM), fat mass (FM), and body build after 12 wk of weight training

\begin{tabular}{|c|c|c|c|c|}
\hline & $\begin{array}{c}\text { All Subjects } \\
(N=21)\end{array}$ & $\begin{array}{c}\text { Slender } \\
(N=10)\end{array}$ & $\begin{array}{c}\text { Solid } \\
(N=11)\end{array}$ & $\mid$ dir SI - So | \\
\hline \multicolumn{5}{|l|}{ Absolute changes } \\
\hline $\begin{array}{l}\Delta \text { weight }(\mathrm{kg}) \\
\Delta \mathrm{FFM}(\mathrm{kg}) \\
\Delta \mathrm{FM}(\mathrm{kg})\end{array}$ & $\begin{array}{r}-1.1^{\star} \pm 2.1 \\
0.9^{\star \star} \pm 1.3 \\
-2.1^{\star \star} \pm 1.7\end{array}$ & $\begin{array}{r}-1.5^{\star} \pm 1.7 \\
0.3 \pm 0.9 \\
-1.7^{\star \star} \pm 1.4\end{array}$ & $\begin{array}{r}-0.8 \pm 2.5 \\
1.6^{* \star} \pm 1.4 \\
-2.4^{\star \star} \pm 1.9\end{array}$ & $\begin{array}{l}0.7 \\
1.3^{*} \\
0.7\end{array}$ \\
\hline \multicolumn{5}{|c|}{ Changes relative to pretraining values } \\
\hline $\begin{array}{l}\Delta \text { weight (\%) } \\
\Delta \text { FFM (\%) } \\
\Delta \text { FM }(\%) \\
\Delta \text { body-build }\left(\mathrm{kg} \mathrm{FFM} / \mathrm{m}^{2}\right)\end{array}$ & $\begin{aligned}-1.3^{\star} & \pm 2.5 \\
1.5^{\star \star} & \pm 2.0 \\
-10.9^{\star \star} & \pm 8.4 \\
0.52^{\star \star} & \pm 0.5\end{aligned}$ & $\begin{aligned}-1.9^{\star} & \pm 2.3 \\
0.5 & \pm 1.7 \\
-10.5^{\star \star} & \pm 8.4 \\
0.26^{\star} & \pm 0.3\end{aligned}$ & $\begin{array}{r}-0.9 \pm 2.6 \\
2.3^{\star \star} \pm 2.0 \\
-11.3^{\star \star} \pm 8.8 \\
0.75^{\star *} \pm 0.5\end{array}$ & $\begin{array}{l}1.0 \\
1.8^{\star} \\
0.8 \\
0.49^{\star \star}\end{array}$ \\
\hline
\end{tabular}

Values are means $\pm \mathrm{SD}$ (level of significance: ${ }^{*} P<0.05,{ }^{* *} P<0.01$ ). 
0.001 ), there was no significant correlation between $\Delta F F M$ and $\Delta$ strength. Maximal aerobic power was not influenced by weight training.

Training compliance was similar in the slender and the solid group ( $97.1 \pm 4.4 \%$ and $92.4 \pm 7.4 \%$, respectively). The mean absolute training load during the last 6 wk of the training program differed significantly between the slender and solid group (43.0 $\pm 7.4 \mathrm{~kg}$ vs $51.3 \pm 9.5$ $\mathrm{kg} ; P<0.05$, respectively). However, training load relative to FFM was comparable $\left(0.76 \pm 0.1 \mathrm{~kg} \cdot \mathrm{kg}^{-1} \mathrm{FFM}\right.$ vs $\left.0.73 \pm 0.1 \mathrm{~kg} \cdot \mathrm{kg}^{-1} \mathrm{FFM}\right)$. There was no significant correlation between mean absolute training load and $\Delta F F M$ or $\Delta$ strength (absolute and relative to pretraining values).

\section{DISCUSSION}

The aim of the present study was to investigate the effect of body build on weight-training-induced adaptations in body composition and strength. The physical adaptation in two groups with different body build were compared. The solid group showed a significant absolute and relative increase in FFM $(P<0.05)$. The slender group showed no significant change in FFM. Both groups showed comparable decreases in FM and increases in strength and no change in maximal aerobic power.

The mean increase in FFM for the entire group $(+0.9$ $\mathrm{kg}$ ) is in agreement with findings of other weight-training studies. A review of the literature did not provide any information on the effect of initial differences in FFM on the training response. The few studies that did include initial differences in FFM in their experimental design were primarily focused on differences between sexes. These studies revealed no influence of the initial amount of FFM. In general, men had a larger absolute increase in FFM and strength but percentage increases were similar in both sexes $(2,9)$. The use of different sexes, however, makes these studies less appropriate as data for comparison.

The mean decrease in FM for the entire group ( -2.1 $\mathrm{kg}$ ) was somewhat larger then usually found in comparable weight-training studies (on average $1 \mathrm{~kg}$ ). It cannot be excluded that the training-induced changes in FM and/or FFM were partly be due to changes of energy intake $(5,15)$. However, the poor reliability of methods to measure dietary intake accurately (27) made it little meaningful to record eventual changes in energy intake in the present study. The similar $\Delta \mathrm{FM}$ in both groups suggests that an eventual change in dietary intake could only have had a minor contribution to the measured difference in $\triangle F F M$ between the groups. Furthermore, it is not likely that a change of eating habits would only occur in one of the groups.

Body weight decreased significantly in the slender group as a consequence of a larger discrepancy between the increase in FFM and a decrease in FM $(-1.5 \pm 1.7 \mathrm{~kg})$ compared with the solid group $(-0.8 \pm 2.5 \mathrm{~kg})$. The large standard deviation indicates the interindividual variation in $\Delta$ weight. These data demonstrate the limited validity of $\Delta$ weight as a parameter to evaluate dietary or training interventions since it masks adaptation in FFM and FM.

At the beginning of the program the solid group was stronger than the slender group. The initial amount of FFM correlated significantly with strength $(P=0.001)$. This is in agreement with other studies showing that strength is primarily determined by the quantity of FFM and the physiological cross-section of the muscle $(13,19,28)$. In spite of this relationship, no significant correlation was found between the increase in FFM and the increase in strength. Surprisingly, the slender group had a comparable increase in strength without a change in FFM. This discrepancy between $\Delta$ strength and $\Delta F F M$ may partly be attributed to the process of neural adaptation to training (20). In the beginning of a training program neural adaptation, if compared with muscular adaptation (hypertrophy), accounts for the larger proportion of the strength increment $(14,16)$. The contribution of muscle hypertrophy increases slowly during the training period and after 3-6 wk becomes the dominant factor. The magnitude of the contribution of neural factors depends on the familiarity with the performed movement or test protocol. The difference in strength gain between the everyday knee extension movement $(8.8 \pm 7.0 \%)$ and the atypical knee flexion $(15.3 \pm 11.2 \%)$ and bench press $(17.1 \pm 9.9 \%)$ movement is in concordance with this latter finding. Another factor that might partly explain the discrepancy found between $\triangle F F M$ and $\Delta$ strength is the specificity of the strength tests. Each test measures $\Delta$ strength in the muscle groups involved in contrast with the increase in FFM which was presumably distributed all over the body. The interindividual variation in the contribution of neural adaptation and $\triangle F F M$ to the increase in strength might explain the lack of a significant correlation between $\triangle F F M$ and $\Delta$ strength.

This study applied a nearly unknown method to describe body build. The reason for not using a more commonly used method to classify humans by their physical shape lies in the fact that these methods use skinfolds and girths $(1,8)$. These descriptions mostly fit the visual perception but do not make a clear distinction between FFM and FM. Furthermore, studies revealed the limited accuracy of girths to estimate the total amount of or changes in FFM (28). The reliability of the present method to describe body build is restricted to the precision in the determination of body composition and the measurement of height. The application of the height-normalized index FFMI appeared to be an appropriate method to eliminate differences in height (correlation FFM and height: $\mathrm{r}=$ $0.65, P<0.001$; correlation FFMI and height: $\mathrm{r}=-0.1$, $P=0.19 ; N=77)$. Further, the quantitative relationship in this study between FFM and FM was in agreement with findings of other studies. Dietary intervention studies revealed that FFM contributes for a quarter to a third to 
changes in body weight (7). The classification of body build by the extent to which a person's FFMI differs from the regression of FFMI over FMI seems a workable method to distinguish between individuals with different height-normalized quantities of FFM and FM. The difference in FFM between the slender and solid group was $13.3 \mathrm{~kg}$ FFM. However, this method is only usable if a valid reference regression equation of FFMI over FMI is available.

This study used several exclusion criteria in combination with a specific definition of body build to eliminate well-known determinants of a training response like age $(12,17,21)$, sex (25), absolute quantity of fat mass (6), and the initial level of training (21). The training stimulus as determinant differed, with respect to the mean training load, between the groups. This was mainly the consequence of the intergroup difference in FFM. The mean absolute training load, however, was not significantly correlated with $\triangle F F M$. Therefore, it seems plausible that the difference in $\triangle F F M$ between both groups is due to the initial difference in body build. The data of the present study, however, do not explain the underlying mechanism responsible for this difference in $\triangle F F M$. A genetic determined potential to increase FFM seems a possible explanation which also could explain the initial differences in body build. Some investigators reported a preferential hypertrophy of type II fibers (4) in weight-trained subjects, suggesting a fiber-type composition modified ad-

\section{REFERENCES}

1. BEHNKe, A. R. and J. H. WiLmore. Evaluation and Regulation of Body Build and Composition. Englewoods Cliffs, NJ: PrenticeHall, 1974, pp. 75-81.

2. Cureton, K. J., M. A. Collins, D. W. Hill, and F. M. MCElHANNON. Muscle hypertrophy in men and women. Med. Sci. Sports Exerc. 20:338-344, 1988.

3. Durnin, J. V. G. A. and J. Womersuley. Body fat assessed from total body density and its estimation from skinfold thickness: measurements on 481 men and women aged from 16 to 72 years. Br. J. Nutr: 32:77-97, 1974.

4. Faulkner, J. A. and T. P. White. Adaptations of skeletal muscle to physical activity. In: Exercise, Fimess, and Health: a Consensus of Current Knowledge. C. Bouchard, R. J. Shephard, T. Stephens, J. R. Sutton and B. D. McPherson (Eds.). Champaign, IL: Human Kinetics Publishers, 1990, pp. 265-279.

5. FORBES, G. J. Body composition as affected by physical activity and nutrition. Fed. Proc. 44:343-347, 1985.

6. Forizes, G. B. Exercise and body composition. J. Appl. Plysiol. 70:994-997, 1991.

7. Forbes, G. B. The companionship of lean and fat: some lessons from body composition studies. In: New Techniques in Nutritional Research. R, G. Whitehead and A. Prentice (Eds.). San Diego: Academic Press, 1991, pp. 317-329.

8. Henth, B. H. and J. E. L. CArTtir. A modilied Somalotype method. Am. J. Plyss. Anthrop. 27:57-74, 1967.

9. HollowAY, J. B. and T. R. BAECHLE. Strength training for female athletes. A review of selected effects. Sports Med. 9:216-227, 1990.

10. KATCH, F, I. and V. L. KATCH. The body composition profile. Techniques of measurement and applications. Clin. Sports Med. 3:31-63, 1984.

11. KАTCH, F. I. and S. S. Drumm. Effects of different modes of aptation to weight training. Another possible explanation lies not so much in the capacity to produce FFM, which refers to the final amount of FFM, but in a difference in adaptation speeds. This hypothesis can be tested by prolonged weight-training studies with several intermediate measurements.

In conclusion, the data of the present study indicate that body build, defined as the initial quantity of fat-free mass corrected for fat mass and height, modifies the weighttraining-induced changes in FFM. After 12 wk of weight training, individuals with a solid body build increased their FFM whereas slenderly built individuals did not show a significant change in FFM. The data confirm earlier studies that weight training is an appropriate method to increase muscular strength and to decrease FM. Additional research over a longer period is needed to confirm and extend these findings and to study the mechanism responsible for differences in weight-training-induced changes in FFM. Reference values for various populations (e.g., males/females, trained/sedentary or age groups) based on large numbers of subjects should be determined to enable other investigator to utilize and implement FFMI and FMI in describing their study subjects.

Address for correspondence: Ludo M. L. A. van Etten, Institute of Movement Sciences, University of Limburg, P.O. Box 616, $6200 \mathrm{MD}$ Maastricht, The Netherlands.

strength training on body composition and anthropometry. Clin. Sports Med. 5:413-459, 1986.

12. LARSON, B. Physical training effect on muscle morphology in sedentary males at different ages. Med. Sci. Sports Exerc. 14:203206, 1982.

13. Maughan, R. J. Relationship between muscle strength and muscle cross-sectional area: implications for training. Sports Med. 1:263$269,1984$.

14. McDonagh, M. J. N. and C. T. M. Davies. Adaptive response of mammalian skeletal muscle to excreise with high loads. Eur. J. Appl. Physiol. 52:139-155, 1984.

15. Meredith, C. N., W. R. Frontera, K. P. O'Reilly, and W. J. Evans. Body composition in elderly men: effect of dietary modification during strength training. J. Am. Geriatr: Soc. 40:155-162, 1992.

16. Moritani, T. M. A. and H. A. Devries. Neural factors versus hypertrophy in the time course of muscle strength gain. $A m . J$. Phys. Med. 58:115-130, 1979.

17. Pollock, M. L., G. A. DAwson, H. S. Miller, et al. Physiologic response of men 49 to 65 years of age to endurance training. J. Am. Geriatr: Soc. 24:97-104, 1976.

18. Reid, C. M., R. A. YeAter, and I. H. UlLrich. Weight training and strength, cardiorespiratory functioning and body composition of men. Br. J. Sports Med. 21:40-44, 1987.

19. Ryushi, T., K. Häkkinen, H. Kauhanen, and P. V. Komi. Muscle fiber characteristics, muscle cross-sectional area and force production in strength athletes, physically active males and females. Scand. J. Sports Sci. 10:7-15, 1988.

20. SAle, D. G. Neural adaption to resistance training. Med. Sci. Sports Exerc. 20(Suppl.):S135-S145, 1988.

21. Saltin, B., L. Hartley, A. Kilbom, and I. Åstrand. Physical 
training in sedentary middle-aged men. II. Oxygen uptake, heart rate, and blood lactate concentration at submaximal and maximal exercise. Scand. J. Clin. Lab. Invest. 24:323-334, 1969.

22. Slattery, M. L. and D. R. JacoBs. The inter-relationships of physical activity, physical fitness, and body measurements. Med. Sci. Sports Exerc. 19:564-569, 1987.

23. Tremblay, A., J-P. Després, C. Leblanc, et al. Effect of intensity of physical activity on body fatness and fat distribution. Am. $J$. Clin. Nutr. 51:153-157, 1990.

24. Vanittallie, T. B., Mei-Uih Yang, S. B. Heymsfield, R. C. Funk, and R. A. BolleAu. Height-normalized indices of the body's fat-free mass and fat mass: potentially useful indicators of nutritional status. Am. J. Clin. Nutr: 52:953-959, 1990.

25. Wells, C. L. Women, Sport and Performance: A Physiological
Perspective. Champaign, IL: Human Kinetics, 1985, pp. 239-240.

26. Westerterp, K. R., G. A. L. Meijer, A. D. M. Kester, L. WoutERS, and F. TEN HOOR. Fat-free mass as a function of fat mass and habitual activity level. Int. J. Sports Med. 13:163-166, 17-22, 1992.

27. Westerterp, K. R, W. P. H. G. Verboeket V/D Venne, G. A. L. MEIJER, AND F TEN HoOR. Self-reported intake as a measure for energy intake. A validation against doubly labeled water. In: $O b e-$ sity in Europe 91. G. Ailhaud, et al. John Libbey \& Company, Ltd., 1992, pp. 17-22,

28. Young, A., M. STokes, J. M. Round, and R. H. T. Edwards. The effect of high-resistance training on the strength and cross-sectional area of the human quadriceps. Eur. J. Clin. Invest. 13:411$417,1983$.

\section{CORRIGENDUM}

The authors for article "Dynamic performance assessment of selected sport shoes on impact forces" 23(9):1062-1067, 1991, should be listed as J. S. Dufek, B. T. Bates, H. P. Davis, and L. A. Malone. 